\title{
A Rare Presentation of Eosinophilic Granulomatosis with Polyangiitis with Diffuse Lymphadenopathy
}

Sean O'Loghlen MD, Joshua Lakoff MD FRCPC, John Garvey MB BCh BAO PhD, David Good MD, Marie Clements-Baker MD FRCPC Correspondence may be directed to: sean.b.ologhlen@gmail.com

\begin{abstract}
About the Authors
Sean O'Loghlen, Joshua Lakoff, and Marie Clements-Baker are with the Queen's University Department of Internal Medicine in Kingston, ON. John Garvey is with St. Vincent's University Hospital in Dublin, Ireland. David Good is with the Queen's University Department of Pathology and Molecular Medicine in Kingston, ON.
\end{abstract}

Corresponding Author sean.b.ologhlen@gmail.com

Submitted: April 19, 2017. Accepted: June 15, 2017. November 7, 2017.

\begin{abstract}
A 56-year-old man, who recently returned from a trip to Guyana, presented to hospital with a 10-week history of neuropathic pain, paresthesias, sinus pain, weight loss, and diffuse lymphadenopathy. Bloodwork was remarkable for significant eosinophilia $\left(6.57 \times 10^{9}\right.$ cells/L), erythrocyte sedimentation rate of $119 \mathrm{~mm} /$ hour and C-reactive protein of $44.3 \mathrm{mg} / \mathrm{L}$. An extensive work up for an underlying lymphoproliferative disorder or infectious process was negative. Anti-MPO ANCA was initially borderline positive at $23 \mathrm{CU}$ but on repeat testing 3 months later was strongly positive at $409 \mathrm{CU}$. He was diagnosed with eosinophilic granulomatosis with polyangiitis (EGPA) and was started on corticosteroids with an excellent clinical response. We review the epidemiology, typical clinical manifestations, diagnostic criteria and management of EGPA.
\end{abstract}

\section{Résumé}

Un homme de 56 ans, de retour récemment d'un voyage en Guyane, se présente à l'hôpital avec des problèmes de douleur neuropathique, de paresthésie, de douleur aux sinus, de perte de poids et d'une adénopathie diffuse qui durent depuis dix semaines. Les analyses sanguines révèlent une éosinophilie importante $\left(6,57 \times 10^{9}\right.$ cellules/L), une vitesse de sédimentation érythrocytaire de $119 \mathrm{~mm}$ après une heure et un taux de protéine C réactive de 44,3 $\mathrm{mg} / \mathrm{L}$. Une recherche poussée relative à la présence d'un trouble lymphoprolifératif sous-jacent ou d'un processus infectieux s'est avérée négative. L'ANCA anti-MPO était tout d’abord légèrement positif à $23 \mathrm{CU}$, mais une nouvelle analyse trois mois plus tard s'est révélée fortement positive, à $409 \mathrm{CU}$. On a alors diagnostiqué une granulomatose éosinophile et une inflammation simultanée de plusieurs vaisseaux sanguins ou lymphatiques (EGPA, pour eosinophilic granulomatosis with polyangiitis). Un traitement aux corticostéroïdes a été entrepris, avec une excellente réponse clinique. Nous passons en revue lépidémiologie, les manifestations cliniques, les critères diagnostiques et la prise en charge de l'EGPA. 


\section{Case Presentation}

A 56-year-old male presented with a 10-week history of pain and paresthesias in his extremities with sinus pain, weight loss, diffuse lymphadenopathy and generalized malaise. Past medical history included a recent left leg deep venous thrombosis diagnosed one month prior and chronic obstructive pulmonary disease (COPD) diagnosed 8 years prior. He had infrequent COPD exacerbations and was symptom free between episodes. Medications included rivaroxaban, salbutamol, tiotropium, and fluticasone/salmeterol. He emigrated from Guyana several years ago, but recently vacationed there.

Physical examination demonstrated cachexia, bilateral cervical and inguinal lymphadenopathy, and hepatomegaly. There were no rashes, swollen joints, or ulcers. There was decreased sensation in the median nerve distribution on the left forearm, the ulnar nerve distribution on the right forearm, and the sural nerve distribution of the left leg. Bloodwork revealed a leukocytosis of $19.9 \times 10^{9}$ cells/L with eosinophilia $\left(6.57 \times 10^{9}\right.$ cells/L). Erythrocyte sedimentation rate was $119 \mathrm{~mm} / \mathrm{hr}$ and C-reactive protein (CRP) $44.3 \mathrm{mg} / \mathrm{L}$. c-ANCA was positive, p-ANCA was negative. Interestingly, his anti-PR3 ANCA titre was within normal limits at $3 \mathrm{CU}$ but his anti-MPO ANCA was borderline positive at $23 \mathrm{CU}$. Chest computed tomography (CT)-scan showed subpleural groundglass opacification in the left upper lobe. Abdominal CT-scan showed thrombosis of the hepatic vein and ischemic changes in the liver parenchyma compatible with Budd-Chiari syndrome. There was bilateral inguinal adenopathy. The patient was admitted to hospital for further investigations for a possible lymphoproliferative disorder, infection, or vasculitis.

Cultures of blood and stool were negative. Interferongamma release assay for tuberculosis was negative. Serology for strongyloides, filiariasis, malaria, human immunodeficiency virus, and human T-cell lymphotropic virus I/II was negative. Electromyography showed a length-dependent neuropathy suggestive of mononeuritis multiplex. Molecular genetic testing for mutations associated with clonal eosinophilic disorders was negative. Bone marrow biopsy demonstrated reactive changes with no malignant cells but significant eosinophilia ( $20 \%$ of all bone marrow cells). An excisional lymph node biopsy revealed a necrotic and hemorrhagic node with vague non-caseating granulomas in the surrounding lymph node capsule (Figure 1). ANCA serology was repeated and anti-MPO ANCA was now strongly positive at $409 \mathrm{CU}$. A sural nerve biopsy was planned, but the patient's symptoms progressed to the point where he was debilitated. He was started on corticosteroids for a presumed diagnosis of eosinophilic granulomatosis with polyangiitis (EGPA). His symptoms improved and his eosinophilia resolved on steroid therapy. Azathioprine was started as his steroid dose was tapered.

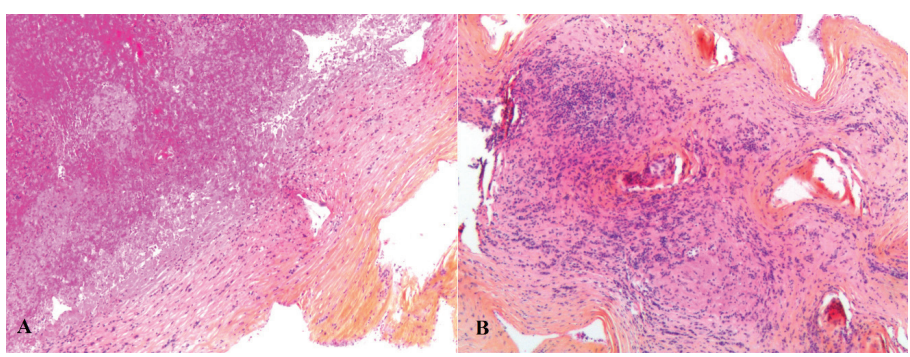

Figure 1. Histopathology from lymph node biopsy. (A) HPS stain at $2 \times$ magnification - Representative section of fibrotic lymph node capsule with adjacent necrotic and hemorrhagic material. (B) HPS stain at $4 \times$ magnification - Representative section of area of lymph node with thickened capsule and vague noncaseating granulomas.

\section{Discussion}

EGPA, formerly known as Churg-Strauss syndrome, is a rare, life-threatening ANCA-associated systemic vasculitis. The annual incidence is estimated at 2.4-6.8 cases per million people. ${ }^{1}$ The disorder was first described by Jacob Churg and Lotte Strauss in 1951, when they published a series of 13 patients who presented with a necrotizing systemic vasculitis, with pathologic evidence of extravascular granulomas and eosinophilia on a background history of asthma and atopy. ${ }^{2}$ The pathophysiology is poorly understood and the role of ANCAs remains controversial. Patients have a prodrome of asthma with progressive development of peripheral eosinophilia, culminating in a life-threatening necrotizing vasculitis affecting small to medium sized vessels. ${ }^{2}$ Airways disease can precede the vasculitic manifestations for several years.

The diagnosis of EGPA is challenging to make. The classic features of eosinophilia, extravascular granulomas and necrotizing vasculitis described by Churg and Strauss rarely co-exist in the same patient at a given time. ${ }^{3}$ Biopsy of an affected organ is recommended but can be falsely negative. ${ }^{1}$

The American College of Rheumatology (ACR) proposed six diagnostic criteria for EGPA: presence of asthma, eosinophilia $>10 \%$, mononeuropathy or polyneuropathy, transient pulmonary infiltrates, paranasal sinus abnormalities, and pathologic confirmation of extravascular eosinophils. ${ }^{4}$ The ACR found that satisfying at least 4 of these 6 criteria yielded a sensitivity of $85 \%$ and specificity of $99.7 \%$ for diagnosing EGPA. ${ }^{4}$ Our patient satisfied at least 4 criteria (eosinophilia $>10 \%$, mononeuritis multiplex, paranasal sinus abnormalities, pulmonary infiltrates). Though our patient was diagnosed with COPD remotely, we suspect he actually had asthma given the absence of symptoms between exacerbations. The timeline of his initial diagnosis with 
airways disease and the development of the vasculitis fits with the natural history of EGPA.

The largest study of patients with EGPA is the French Vasculitis Study Group Cohort. ${ }^{5}$ The study enrolled 383 patients diagnosed with EGPA from 1957-2009. The mean age of subjects was 50.3 years and $98.2 \%$ were Caucasian. ${ }^{5}$ Only $31.0 \%$ were ANCA positive. ${ }^{5}$ Common disease manifestations included peripheral neuropathy, weight loss, otolaryngological symptoms, skin lesions, and pulmonary infiltrates. This case of EGPA is unique because the patient's lymphadenopathy was very pronounced, and he had a history of 2 recently diagnosed deep venous thromboses (left leg DVT and Budd-Chiari syndrome). Venous thromboembolic disease was unusual among the French Vasculitis Study Group patients. ${ }^{5}$ The prevalence of lymphadenopathy in the group was not described by the authors. Lymph node involvement in EGPA has previously been described as exceedingly rare. ${ }^{3}$

EGPA was frequently fatal prior to the development of immunosuppressive therapy. ${ }^{4}$ The prognosis has improved significantly with the advent of glucocorticoids. ${ }^{5}$ Guidelines issued jointly by the British Society for Rheumatology (BSR) and British Health Professionals in Rheumatology (BHPR) for the management of adults with ANCA-associated vasculitis recommends induction therapy with high-dose glucocorticoids and cyclophosphamide or rituximab. ${ }^{6}$ Methotrexate or mycophenolate mofetil are alternative induction agents in non life- or organthreatening disease. ${ }^{6}$ Some sources suggest that glucocorticoid therapy alone is sufficient to induce remission in EGPA in up to $40 \%$ of cases. ${ }^{1}$ Our patient has had an excellent response to glucocorticoids.

\section{References}

1. Noth I, Strek ME, Leff AR. Churg-Strauss syndrome. Lancet 2003;361:587-94. Available at : https://www.researchgate.net/profile/ Imre_Noth/publication/10890522_Churg-Strauss_syndrome/ links/00b7d51472b9156a0e000000.pdf.

2. Choi YH, Im JG, Han BK, et al. Thoracic manifestation of ChurgStrauss syndrome: Radiologic and clinical findings. Chest 2000;117:117-24. Available at: http://citeseerx.ist.psu.edu/viewdoc/ download?doi=10.1.1.631.4908\&rep=rep1\&type=pdf.

3. Casey M, Radel E, Ratech H. Lymph node manifestations of limited ChurgStrauss syndrome. J Pediatr Hematol Oncol 2000;22(5):468-71. Available at: http://journals.lww.com/jpho-online/Abstract/2000/09000/Lymph_Node_ Manifestations_of_Limited_Churg_Strauss.18.aspx.

4. Masi AT, Hunder GG, Lie JT, et al. The American College of Rheumatology 1990 criteria for the classification of Churg-Strauss syndrome (allergic granulomatosis and angiitis). Arthrit Rheumatis 1990 Aug 1;33(8):1094-100. Available at: http://onlinelibrary.wiley.com/doi/10.1002/art.1780330806/pdf.

5. Comarmond C, Pagnoux C, Khellaf M, et al. Eosinophilic granulomatosis with polyangiitis (Churg-Strauss): Clinical characteristics and long-term followup of the 383 patients enrolled in the French Vasculitis Study Group cohort. Arthrit Rheumatis 2013 Jan 1;65(1):270-81. Available at: http:// onlinelibrary.wiley.com/doi/10.1002/art.37721/full.

6. Ntatsaki E, Carruthers D, Chakravarty K, et al. BSR and BHPR guidelines for the management of adults with ANCA-associated vasculitis. Rheumatology 2014;53:2306-9. Available at: https:// academic.oup.com/rheumatology/article/46/10/1615/1788632/ BSR-and-BHPR-guidelines-for-the-management-of. 